\title{
Interfaces entre cultura histórica e cultura política
}

\author{
Luis Fernando Cerri ${ }^{{ }^{*}}$ \\ ${ }^{1}$ Universidade Estadual de Ponta Grossa, Ponta Grossa/PR - Brasil
}

\section{RESUMO}

O panorama atual da pesquisa em cultura histórica no Brasil está em constante desenvolvimento, tanto no campo da história quanto no do ensino da história, entretanto a interface do conceito de cultura histórica com o de cultura política necessita de maior aprofundamento. Este ensaio teórico parte dos conceitos de Jörn Rüsen (cultura histórica) e Gabriel Almond e Sidney Verba (cultura política) e tem por objetivo perscrutar as potencialidades da articulação entre os conceitos visando ao desenvolvimento de estudos sobre as relaçôes entre o pensamento dos indivíduos com a história e a política em suas realidades específicas. O desenvolvimento envolve buscar as combinaçôes entre esses conceitos e decompor e analisar as características, posicionamentos, saberes e atitudes a serem traduzidos em instrumentos de pesquisa quantitativa e qualitativa. Assim, constituirão ferramentas poderosas para seguir qualificando a interpretação, entre outras, das relaçóes de ensino e aprendizagem da história, na busca de coletar dados e contribuir para a compreensão da complexa relação entre escolarização histórica e aprendizagem extraescolar, principalmente no que diz respeito à formação de identidade pessoal, grupal e nacional, associadas à socialização e posicionamento políticos.

Palavras-chave: cultura histórica; cultura política; consciência histórica; teoria da história; didática da história; pesquisa.

DOI: http://dx.doi.org/10.1590/2237-101X02204603

Artigo recebido em $1^{\circ}$ de abril de 2020 e aceito para publicação em 25 de junho de 2020 .

* Professor da Universidade Federal de Ponta Grossa / Setor de Ciências Humanas, Letras e Artes / Departamento de História, Ponta Grossa/PR - Brasil. Bolsista CNPq PQ-2. E-mail: Ifcronos@yahoo.com.br. ORCID: https://orcid.org/0000-0002-9650-0522.

Bolsista de produtividade em pesquisa do CNPq. Pesquisa financiada com recursos do Edital Universal do CNPq 2018. 


\title{
Interfaces between historical and political culture
}

\begin{abstract}
The field of historical culture in Brazil is constantly developing, through both historical research and teaching, , however, the interface between the concept of historical culture and that of political culture needs further study. This theoretical essay uses the concepts of Jörn Rüsen (historical culture) and Gabriel Almond and, Sidney Verba (political culture), and investigates the potential for links between both concepts, in order to address the development of studies on the relationships between individual thought and history and politics. This development involves searching for connections between these concepts, as well as decomposing and analyzing the characteristics, positions, knowledge, and attitudes to be translated into tools to quantitative and qualitative research. These concepts will be powerful tools for qualifying interpretations of, among other subjects, the teaching and learning of history and the quest to collect data and contribute to the understanding of the complex relationship between historical schooling and extra-school learning, mainly with regard to forming personal, group and national identities associated with the socializing processes and political positions.
\end{abstract}

Keywords: historical culture; political culture; historical consciousness; theory of history; history didactics; research.

\section{Interfaces entre la cultura histórica y la cultura política}

\section{RESUMEN}

El panorama actual de investigación sobre cultura histórica en Brasil está en constante desarrollo, tanto en el campo de la historia como en el de la enseńanza de la historia, mientras la interface del concepto de cultura histórica con el de cultura política necesita más intensificación. Este ensayo teórico parte de los conceptos de Jörn Rüsen (cultura histórica), Gabriel Almond y Sidney Verba (cultura política), y tiene por objetivo explorar las potencialidades de la articulación entre los conceptos visando el desarrollo de estudios sobre las relaciones entre el pensamiento de los individuos con la historia y la política en sus realidades específicas. El desarrollo pretende buscar las combinaciones entre esos conceptos para descomponer y analizar las características, posicionamientos, saberes y actitudes a ser traducidos en instrumentos de investigación cuantitativa y cualitativa. De esta forma, constituirán herramientas poderosas para seguir calificando la interpretación, entre otras, de las relaciones de enseñanza y aprendizaje de la historia, en la búsqueda de colectar datos y contribuir para la comprensión de la compleja relación entre escolarización histórica y aprendizaje extraescolar, principalmente en lo que respecta a la formación de la identidad personal, grupal y nacional, asociadas a la socialización y posiciones políticas. 
Palabras clave: cultura histórica; cultura política; consciencia histórica; teoría de la historia; didáctica de la historia, investigación.

\section{Cultura política, cultura histórica: pontos de contato}

A cultura política é o conceito que expressa os padrôes pelos quais uma sociedade se relaciona com as esferas em que as decisôes coletivas são tomadas. Assim, é de se pressupor que as características mais amplas de cada cultura condicionem as particularidades que caracterizam dinamicamente cada cultura política ou, dizendo de outro modo, uma vez que as culturas são particulares e específicas, o componente político delas também é específico, em interação dinâmica com os demais componentes dessa cultura. Assim, do mesmo modo que se pode falar de uma cultura brasileira, de uma cultura regional ou da cultura política de um grupo específico dentro de uma sociedade, também se pode falar em cultura política brasileira e em uma cultura política, por exemplo, mineira ou gaúcha.

No que tange à sua estrutura e componentes, a cultura política pode ser definida (considerando principalmente os aspectos macro da vida em sociedade) como

[...] os valores e crenças partilhados por um grupo ou sociedade relativos aos relacionamentos políticos e políticas públicas [que] respondem à questão de quem tem que fazer o que com quem e para quem sob que circunstâncias. A cultura política também responde à questão de quem decide, quem tem autoridade e quem tem $\operatorname{poder}^{1}$ (SWEDLOW, 2012, p. 624).

Há uma concordância entre grande parte dos autores da ciência política de que a obra The civic culture: political attitudes and democracy in five nations (ALMOND; VERBA, 1989) tem um peso inaugural no estabelecimento do campo de estudos da cultura política. A obra, originalmente publicada em 1963, é marcada pela tradição funcionalista estrutural no aspecto teórico e pela preocupação com os processos disruptivos da democracia perante a concorrência de projetos distintos, como o socialismo soviético ou chinês, no aspecto contextual das disputas da Guerra Fria. Em suma, o problema colocado pelos autores era levantar quais as características da cultura política capazes de sustentar um padrão democrático e liberal, espelhado principalmente na Grã-Bretanha e nos Estados Unidos, tendo Alemanha e Itália, recém-saídas de regimes totalitários, e o México, como contrapontos. O objetivo era subsidiar açóes pró-democracia ocidental, diante da crise da ideia de que os valo-

\footnotetext{
${ }^{1}$ Tradução livre do autor. No original: "the shared values and beliefs of a group or society regarding political relationships and public policy - answers the question of how human beings are going to live together. That is, political culture answers the question of who gets to do what with and to whom under what circumstances. Political culture also answers the question of who decides, who has authority, and who has power in a group, organization, institution, or other social unit in society".
} 
res iluministas avançariam inexoravelmente (ALMOND; VERBA, 1989, p. 4), varrida pela ascensão dos totalitarismos e das tragédias da Segunda Guerra Mundial. O funcionalismo estrutural data do final do século XIX, em que as Ciências Sociais procuravam dar conta dos processos de intensa mudança social que afetavam sua época (urbanização, industrialização, movimentos políticos e sociais de massa) e ameaçavam a integridade das sociedades. Para os estruturalistas funcionalistas, a sociedade poderia ser descrita a partir das funçóes sociais, que segundo Émile Durkheim, podem ser investigadas identificando as necessidades às quais correspondem e as instituiçóes existentes para atendê-las. Dessa influência decorre, segundo Pavone (2014), uma teoria funcionalista estrutural da cultura política, baseada na busca de entender e caracterizar as necessidades sociais nesse campo, ou seja, as orientaçóes políticas individuais, e as funções (sistema político, burocracias, legislaturas, políticas públicas) que buscam supri-la.

As críticas à proposição teórica e à aplicação metodológica da categoria de cultura política por Almond e Verba referem-se a cinco tópicos principais: determinismo cultural anglo-saxônico ao definir os padrôes de democracia, carência de racionalidade e parcimônia adequada no estabelecimento dos objetos, extrapolação de características nacionais a partir de evidências de pesquisa que ficam no nível individual e, por fim, amplitude excessiva, com milhares de entrevistados (PAVONE, 2015, p. 1). Essas críticas foram respondidas pelos autores quase quarenta anos depois do lançamento da obra, em um novo livro (ALMOND; VERBA, 1980) no qual, em síntese, rejeitam e contra-argumentam as críticas aos aspectos teóricos e aceitam parcialmente as críticas aos aspectos metodológicos.

Para os fins deste trabalho é importante destacar que a proposta de estrutura dos componentes e lógicas de funcionamento da cultura política de Almond e Verba náo foi objeto de críticas significativas, e ainda pode ser considerada válida para a reflexão que estamos buscando estabelecer neste texto. Almond e Verba estabelecem que o usufruto de uma cultura política específica proporciona orientação aos indivíduos em três âmbitos: o cognitivo, o afetivo e o avaliativo. A “orientação cognitiva” significa o grau de conhecimento que os cidadãos têm do sistema político e a crença nesse sistema, nos seus papéis e nos seus titulares, seus inputs (como as demandas políticas dos cidadãos chegam ao sistema e são processadas) e outputs (como o sistema político responde às demandas). A “orientação afetiva” se traduz pelos sentimentos sobre o sistema político, seus papéis, pessoas e desempenho. Por fim, a "orientação avaliativa" se refere ao julgamento e às opinióes sobre o sistema político (ALMOND; VERBA, 1989). No que se refere aos tipos de cultura política, os autores indicam três tipos ideais, quais sejam, a paroquial, a de sujeição e a participante (ou cultura cívica). A cultura paroquial é congruente com estruturas políticas tradicionais (geralmente de pequenas dimensões, como o feudo, a aldeia, a vila); a de sujeição, com estruturas políticas autoritárias e centralizadas; e a participante, com uma estrutura política democrática. Embora tenha sido alvo de muitas críticas, como indicamos acima, em razão do determinismo cultural implícito na metodologia e nos critérios de escolha das variáveis, o estudo é 
referência na área e suas deficiências acabaram fomentando novas pesquisas, que, de certo modo, tentaram superar as limitaçôes e incongruências verificadas. A principal alteração neste campo de estudos da cultura para compreender o comportamento e a participaçáo política é a emersão de um modelo no qual se estabelece que não há apenas uma cultura cívica que seja exclusivamente congruente com o modelo democrático, bem como se estabelece, em contraponto a Almond e Verba, o papel da indignação e da assertividade dos cidadáos contra seu sistema político como modelo de análise, quando aqueles autores destacavam um modelo de democracia em que prevalecia a lealdade e o conformismo em relaçáo ao sistema (BORBA; CARDOSO, 2019, p. 4). Outros avanços significativos se encontram no estabelecimento da democracia substantiva (e não apenas formal) como padrão orientador das análises do campo, bem como o reconhecimento das tensóes entre liberalismo e democracia (CABRERA CABRERA, 2019, p. 7).

Por sua vez a cultura histórica não é uma discussão nova no Brasil, pois ganhou destaque no ambiente historiográfico principalmente a partir dos anos 2000. Em geral, essa discussão mantém historicamente laços com a reflexão sobre o ensino da história (por exemplo em NEVES, 2001), podendo ter mais ou menos conexôes com os pesquisadores deste campo que "procura inventariar a articulação entre o processo histórico e a produção, transmissão e recepção do conceito conhecimento histórico" (FLORES, 2007, p. 84).

Uma outra frente de destaque no estudo das relaçôes entre cultura, história e política foi formado ao redor de Raquel Soihet e do Núcleo de Pesquisas em História Cultural (Nupehc) nos anos 1990, inicialmente voltado à pesquisa e divulgação da história cultural. No desenvolvimento dos trabalhos, o grupo se aproximou de pesquisadores e pesquisas envolvidas com uma nova história política preocupada com as relaçôes entre política e cultura, que dão mais profundidade e complexidade ao campo, afastando-se da história factual tradicional. No final dessa década, a preocupação em entender e dialogar com os então recém-publicados Parâmetros Curriculares Nacionais promoveu paulatinamente a aproximaçáo desse grupo com as discussôes sobre o ensino de história, de modo ainda incipiente.

Para os fins deste texto a contribuiçẫo do Nupehc mais relevante é a definição e constituição da cultura histórica como categoria, conceito e objeto de pesquisa. Angela de Castro Gomes (2007), ao buscar delimitar a categoria de cultura histórica, aprofundando suas reflexôes anteriores (GOMES, 1998), destaca a interação dinâmica entre as duas expressôes: se, por um lado, a formação (mas também a fabricação a partir de iniciativas estatais, particularmente as autoritárias) da cultura política é um tema para a história, também os conteúdos e referências históricas escolhidos para fabricar a cultura política ("nosso passado") indicam cultura(s) histórica(s) em movimento. Isso fica mais claro quando Gomes reconhece que a cultura histórica, embora relacionada com a cultura historiográfica ${ }^{2}$ de uma época, vai muito além dela (GOMES, 2007, p. 48).

\footnotetext{
${ }^{2}$ A cultura historiográfica pode ser definida como o conjunto de padrôes de pensamento e açáo de pesquisa a partir dos resultados dos trabalhos de historiadores em um dado momento histórico.
} 
O grupo de pesquisa Oficinas da História, sediado na Universidade Estadual do Rio de Janeiro é outro exemplo institucional de debate continuado envolvendo o conceito de cultura histórica, entre outros. Com efeito, os diversos encontros promovidos e livros publicados abordaram diretamente ou dialogaram com a cultura histórica, colocando a problemática entre as principais preocupaçóes desse coletivo e seus interlocutores. Exemplos desse trajeto podem ser registrados nos textos de Gasparello (2009), Rocha et al. (2015) e outros. Num período parecido, a expressão "cultura histórica" consolidou sua cidadania no campo dos estudos sobre o ensino de História por influência das leituras de Jörn Rüsen (ver, entre outros, WANDERLEY, 2012; SCHMIDT, 2012, 2014; OLIVEIRA; OLIVEIRA, 2014; SOUZA, 2014; MARTINS, 2016).

Consideradas brevemente as notas acima, sobre surgimento e desenvolvimento dos conceitos ou categorias cultura política e cultura histórica, interessa-nos neste momento refletir sobre instrumentos teóricos que permitam elaborar quadros metodológicos os quais, por sua vez, uma vez aplicados, possam retroalimentar a reflexão teórica. Um dos componentes que nos interessa de partida é o processo educativo envolvido, especialmente em termos de seus resultados. Por isso, é necessário não perder de vista que a existência da cultura política e da cultura histórica dependem de processos de socialização política (SWEDLOW, 2012, p. 625) e socialização histórica que se dão em processos escolares, mas também em diversos outros âmbitos sociais, momentos e oportunidades da vida do indivíduo/cidadão. Isso é ainda mais válido se tratamos de processos históricos na modernidade, marcada por sucessivos descentramentos e recentramentos, ou ainda se tratamos da modernidade tardia, pós-modernidade ou modernidade líquida, em que as mudanças são ainda mais aceleradas e demandam reaprendizagem e readaptação constante aos novos cenários e configuraçóes histórico-político-culturais.

Diante desses desafios, consideramos que a formulação de cultura histórica de Jörn Rüsen, por seu detalhamento e por suas características estruturais, fornece um referencial teórico potente para o desenho de instrumentos metodológicos que permitam a captura e a análise de elementos da cultura histórica conforme a perspectiva delimitada acima. Além disso, consideramos que há pontos de contato significativos com a caracterização dos componentes da cultura política propostos por Almond e Verba os quais, guardada a devida reserva quanto às suas filiaçôes e objetivos originais, permitem desenhar uma articulação entre cultura histórica e cultura política com a finalidade de pensar instrumentos de análise para ir além da superfície de fenômenos contemporâneos. Adicionalmente, embora a cultura política exerça um papel fundamental na orientação dos cidadãos, é preciso considerar que esse campo da experiência humana não encerra em si toda a orientaçáo do pensamento e das atitudes (RÜSEN, 2007, p. 121).

O conceito de cultura histórica para Rüsen depende do conceito de consciência histórica, que por sua vez pode ser resumido como o fenômeno do pensamento humano pelo 
qual se atribui significado ao tempo, articulando a experiência do passado, a percepção e a necessidade de ação no presente e a projeção de avaliaçóes e intençôes para o futuro. A cultura histórica é definida pelo autor como a expressão visível e coletiva da consciência histórica: "Cultura histórica é o suprassumo dos sentidos constituídos pela consciência histórica humana” (RÜSEN, 2015, p. 217). O conceito busca traduzir um fenômeno social que é a origem primeira da própria historiografia, uma vez que antes e paralelamente a ela, as pessoas e as sociedades produzem sentidos e formas de orientação. Ao serem compartilhados em processos de socializaçáo dos novos membros do grupo, ou reforçados por meio de artefatos culturais (narrativas orais, objetos, monumentos, cançôes, livros, museus etc.), tais sentidos e orientaçôes produzem identidades fundamentais para a coesão e o funcionamento de uma sociedade. Logicamente, isso não isenta o processo - sobretudo na modernidade do componente do conflito, da desagregação e de transformaçóes abruptas, mas isso apenas reforçará a necessidade de revisão e reacomodação da cultura histórica.

Embora não seja objeto da historiografia, a cultura histórica é o próprio substrato do qual surge o historiador e no qual a historiografia se desenvolve, e é razoável propor que ela seja objeto de uma reflexão no campo da história, a cargo, possivelmente, de um ramo da Teoria da História com preocupações didáticas em sentido amplo, qual seja, o dos processos de ensino e aprendizagem que são inerentes a toda socialização e formação histórica, escolar ou não, formal ou não.

Se é na cultura histórica que os indivíduos naturalmente se orientam em meio à passagem e às transformaçóes do tempo, supóe-se que os resultados da ciência da história possam adicionar conteúdo e racionalidade àquela orientação. Note-se que, do modo que estamos formulando, já há conteúdo e alguma forma de racionalidade na orientação antes do aporte da ciência. Com conhecimento resultante da ciência histórica, a orientação dos sujeitos ganha no aspecto cognitivo, mas para Rüsen, esse é apenas um dos aspectos que constituem a cultura histórica. $\mathrm{O}$ conhecimento, para ser válido e útil, precisa integrar-se com outros aspectos, o estético e o político, de tal modo que não podem ser concebidos separadamente (RÜSEN, 2007, p. 121) e as diferentes relaçôes entre esses aspectos, incluindo mesmo a instrumentalização de um sobre o outro (por exemplo, a instrumentação do aspecto cognitivo, a ciência, pela política) caracterizam a cultura histórica e suas dinâmicas (RÜSEN, 2007, p. 125). Além dos aspectos cognitivo, político e estético da cultura histórica, em obra posterior, Rüsen estabelece estas e mais duas dimensóes, a moral e a religiosa (RÜSEN, 2015, p. 235), adicionando outras facetas a considerar na abordagem desse fenômeno.

A estruturação do conceito de cultura histórica por Rüsen permite caracterizar o fenômeno de modo que este se torna permeável, do ponto de vista das alternativas temáticas e metodológicas, a dois aspectos centrais de nossa reflexão. Em primeiro lugar, essa caracterização estabelece uma ponte sólida para pensar de modo estruturado as relaçóes entre a cultura mais ampla e a cultura escolar em particular, ou, dizendo de outro modo, entre a cultura histórica e os 
processos educacionais de socialização/formação inicial e continuada dos membros da sociedade. Desse modo se pode estruturar um olhar da história sobre o ensino e a aprendizagem e seus artefatos que não seja meramente de fonte histórica encapsulada no passado para construção de um discurso historiográfico, mas sim um olhar de reflexão didática (BERGMANN, 1990). Nela, o ensino e a aprendizagem históricos e suas manifestações em artefatos culturais (escolares e não escolares) pode ser capturada em sua interação dinâmica com o tempo presente.

\section{Interfaces}

Para pensar as interfaces entre cultura histórica e cultura política, precisamos restringir o conceito de cultura para um de seus sentidos possíveis: o sentido de orientação psicológica em relação a objetos e relaçóes. A orientação se refere aos aspectos internalizados ou internalizáveis desses objetos e relações e, portanto, é indispensável à compreensão do fenômeno a consideração de processos iniciais e continuados de educação e socialização política e histórica. Neles, as instituiçóes escolares cumprem um papel específico nas sociedades contemporâneas, mas não sozinhas.

Só podemos falar em cultura política porque há um conjunto de elementos da cultura que não pode ser considerado político, pois se a cultura política descrevesse toda a cultura, o conceito não faria sentido, seria incapaz de descrever e caracterizar um fenômeno. Dizer que a política está em tudo não é o mesmo que dizer que tudo é política. O conjunto de objetos e processos para os quais a cultura política orienta refere-se, por um lado, ao sistema político do qual se participa e, por outro, à compreensão de si mesmo como agente/ paciente integrante desse sistema. O sistema político é composto por estruturas ou papéis específicos (corpos legislativos, executivos ou burocracias), responsáveis por papéis (chefes de estado e de governo, legisladores, administradores) e políticas públicas específicas (que envolvem tomada de decisôes ou execução/fiscalização de decisões) (ALMOND; VERBA, 1989, p. 14).

Por sua vez, a cultura histórica só é um conceito viável se identificarmos a que ela se refere, e a que ela não se refere, ou seja, distinguir entre atitudes históricas e não históricas, objetos de cultura histórica e objetos de cultura que não se referem à história. Isso não quer dizer que a história seja irrelevante para elementos da cultura não tratados como históricos. A rigor, todo elemento da cultura está na história e, portanto, ligado a um tempo determinado, estabelecendo relações com o passado e o futuro. Não é disso que se trata.

A cultura histórica refere-se a atos ou objetos de cultura em que a perspectiva do tempo e sua interpretação são tematizados e recebem sentido e significado, geralmente a partir de uma narrativa, mas também concentrados em símbolos ou decisóes. O conteúdo da cultura histórica não se restringe àquilo que é considerado história como objeto de pesquisa para 
o historiador (tudo pode ser objeto, potencialmente, mas na prática da cultura historiográfica contextualizada, nem tudo é objeto). Porém, o conteúdo da cultura histórica não se estende a tudo o que possa ser narrado e articulado no tempo: delimitam-se os conteúdos significativos, progressivamente, para coletividades cada vez mais abrangentes, e obviamente variam conforme as especificidades dos subgrupos dentro de uma sociedade.

Analogamente, embora exercer ou sofrer a ação do poder esteja em todos os âmbitos da vida social, a cultura política se refere a orientações para atos ou objetos referentes ao agir/ sofrer ação em relaçáo ao poder, especialmente em termos de coletividades, ainda que se possa falar em micropolítica. É exatamente o fato de que há um forte componente histórico na cultura política e um forte componente político na cultura histórica que estamos postulando neste texto.

Podemos esboçar alguns elementos que compóem o conjunto de objetos e processos para os quais a cultura histórica orienta, seguindo a pista de Almond e Verba. Chamemos provisoriamente esse conjunto de "concepção de história", que contemplaria uma orientação em relação à história e uma orientação em relação ao próprio papel na história, orientaçóes aliás interdependentes. A concepção do próprio papel na história depende da concepção de história, no seguinte sentido: a história se divide entre a história à qual pertenço, da qual me sinto integrante (ou "dentro", ativa ou passivamente) e a história externa, aquela com a qual a minha relação de pertencimento é nula ou bastante indireta. Dentro de uma mesma sociedade, por exemplo, determinados grupos podem se pensar/sentir completamente integrados à sua história nacional, enquanto imigrantes recentes ou setores economicamente excluídos por gerações podem ter uma relação de exterioridade mais destacada. Pode-se pensar/sentir um maior distanciamento com a história distante no tempo ou, pelo contrário, no caso de saudosismos no presente (monarquistas brasileiros, comunistas russos pró-URSS, católicos medievalistas), sentir-se/pensar-se como estrangeiro em seu próprio tempo. Mesclam-se os aspectos afetivos (estéticos) e cognitivos.

Por um lado, a cultura política é composta pelos padróes de relacionamento com as esferas decisórias de um grupo ou sociedade. Por outro, a cultura histórica é composta pelos padróes de relacionamento com o tempo, principalmente o passado, e seus processos de identificação. O principal ponto de contato entre esses conceitos é a produção de identidades e identificações, fundamental no posicionamento político, e resultante direta dos processos de consciência histórica, que por sua vez produzem e são condicionados pela cultura histórica.

Pressupóe-se a existência de tipologias da cultura política e da cultura histórica. Considerando as tipologias, nem todos os objetos da cultura política coincidem com elementos da cultura histórica, mas todo objeto atinente à dimensão política da cultura histórica participa da cultura política de seu espaço, tempo e grupo social. Assim, a primeira tarefa para os estudos que busquem abordar essa interface é compreender como operam as narra- 
tivas históricas referentes à comunidade política em que se desenvolvem. Essas narrativas são náo raro objeto de disputa, tanto mais profundamente quanto maior a situaçáo de instabilidade e crise, por exemplo no que toca a identidade nacional e suas características, sobre eventos e processos passados que são considerados definidores de valores e condiçôes do grupo político.

O estudo sobre as interaçôes entre cultura política e cultura histórica tem diante de si um conjunto de perguntas que demandam aprofundamento, tanto teórico quanto empírico. Para os levantamentos empíricos, por sua vez, é necessária a concepção e desenvolvimento de metodologias e instrumentos consistentes com os pressupostos teóricos. Tal desenvolvimento implica fazer uma série de perguntas, delinear hipóteses e testá-las, retornando às perguntas para começar a traçar algumas afirmaçôes iniciais e provisórias. Por exemplo: existe um correspondente na cultura histórica da "cultura cívica" proposta por Almond e Verba para a cultura política? Para esses autores, a cultura cívica seria aquela marcada pela participação dos cidadáos em um sistema democrático; portanto os padróes democráticos e participativos seriam, ao mesmo tempo, pré-condição para a cultura cívica, e uma exigência dela, o que daria partida a um círculo virtuoso. Em que pesem todas as ressalvas e críticas possíveis à noção de cultura cívica, parece-nos viável assumir como possível um padrão ideal mínimo de cultura política de convivência democrática, por mais que seja histórico, em movimento, diverso, sujeito a múltiplas negociaçôes. Que tipo de cultura histórica corresponderia a esse modelo de cultura política? Podemos apontar, preliminarmente, que as pré-condiçôes de uma cultura cívica participante e democrática são parecidas com as pré-condiçôes para o estabelecimento da ciência moderna:

a. reconhecimento da legitimidade das diferentes posiçóes desde que assumidas determinadas regras do jogo;

b. estabelecimento, por comum acordo, de procedimentos pelos quais se define e se disputa e se revisa constantemente a posição dominante;

c. laicidade e assunçáo dos pressupostos da razão como orientadores das açôes que interessam a todos, com a devida tolerância para as posiçóes particulares;

d. salvaguardas contra as posiçôes que proponham a destruiçấo do próprio sistema acima, excluindo do campo do diálogo aqueles que burlam os compromissos e regras para sequestrar partes do procedimento para impor posiçōes particulares à coletividade.

Se aceitarmos que esse programa mínimo está na base tanto da ciência quanto da democracia moderna, decorre um modelo de cultura histórica correspondente, que se sustenta nos aspectos cognitivos, estéticos e políticos típicos do modo genético de produção de sentidos históricos, ou seja: 
a. o reconhecimento da historicidade e, portanto, da relatividade de todas as narrativas históricas;

b. a consciência de que, ao longo da história, e mais intensamente na modernidade e na pós-modernidade (ou modernidade líquida, ou modernidade tardia), a mudança é a principal constante, portanto o critério de legitimidade não é sozinho nem a tradição, nem a análise de situaçóes parecidas no passado, e nem algum princípio subjacente que possa revolucionar toda a visão de mundo, mas o reconhecimento de que os interesses são históricos, datados, e a definição dos critérios deve considerar essa relatividade que nos constitui e abrir-se para a dimensão da liberdade de escolha em perspectiva dialógica;

c. a socialização para a cultura histórica em consonância com esse padrão não segue o método e o conteúdo catequéticos, no qual verdades são assimiladas pela memória de modo mecânico, mas exige o conhecimento e o exercício dos rudimentos do método histórico e da análise crítica de todos os enunciados, o que, por sua vez, é uma habilidade que se aproveita também na vida política para o exercício democrático da cidadania;

d. o respeito a visões históricas particulares (religiosas, familiares etc.) ao que corresponde o dever de conhecer os elementos centrais e consensos mínimos do estágio atual do conhecimento histórico e pautar-se por eles na esfera pública.

Ainda na linha de buscar as interfaces entre os dois conceitos, é relevante especular as possíveis articulaçôes entre as categorias que caracterizam e diferenciam os fenômenos que se busca descrever. No Quadro 1 procura-se esboçar as possíveis correspondências, conforme as discussões desenvolvidas acima.

Quadro 1 - Categorias de diferenciação na cultura histórica e na cultura política

\begin{tabular}{|c|c|c|}
\hline \multirow{2}{*}{$\begin{array}{c}\text { Esferas/âmbitos/modos } \\
\text { (de orientação) }\end{array}$} & Cultura política & Cultura histórica \\
\cline { 2 - 3 } & Afetiva & Estética/Moral/Crença \\
\cline { 2 - 3 } & Cognitiva & Cognitiva \\
\hline \multirow{2}{*}{ Tipos ideais } & Avaliativa & Política \\
\cline { 2 - 3 } & Paroquial & Tradicional, exemplar \\
\cline { 2 - 3 } & De sujeição & $\begin{array}{c}\text { Tradicional, exemplar, } \\
\text { crítica }\end{array}$ \\
\cline { 2 - 3 } & Participativa & Genética \\
\hline
\end{tabular}

Fonte: Elaborado pelo autor a partir das definiçóes de Almond e Verba (1989) e Rüsen (2007).

Os tipos ideais da cultura política (paroquial, de sujeição e participativo) não são encontrados puros na realidade, e o mesmo se aplica aos modos de geração de sentido na cultura histórica. Seus objetos não são, exceto em casos muito pontuais (como em um grupo indí- 
gena específico ainda não contatado, ou em uma aldeia medieval praticamente sem acesso ao mundo exterior, por exemplo), exclusivamente tradicionais, exemplares, críticos ou genéticos. Defendemos que sua inter-relação não se dá pela sucessão de etapas, mas é de caráter evolutivo, no sentido de crescente complexidade e abstração. Por isso, uma situação ou um objeto (um discurso, uma narrativa, um símbolo... ou um meme) em que predomine o modo genético, também pode apelar ao modo tradicional, por exemplo. Uma narrativa que surge crítica pode apelar para modos exemplares ou tradicionais de produção de sentido, uma vez consolidada a sua revolução. O contrário não vale para situaçôes em que a "gramática" e o "vocabulário" ainda estão restritas nos modos mais básicos: uma aldeia medieval em que predominem modos tradicionais e exemplares não usará os recursos dos modos críticos ou genéticos de produção de sentido, por não existirem em sua cultura histórica.

$\mathrm{Na}$ cultura histórica da modernidade, portanto, vigem processos de enunciação de discursos históricos em que os modos de geração de sentido existem mesclados em diferentes proporções, incluindo estágios de desorientação ou confusão da consciência histórica (HELLER, 1993, p. 41) e uso de narrativas geradas no modo crítico intencionadas para superar a predominância de enunciações do modo genético em favor de perspectivas tradicionais e exemplares (por exemplo, os fundamentalismos religiosos e o conservadorismo político de ameaça e ódio à democracia (RANCIÈRE, 2014; LEVITSKY; ZIBLATT, 2018).

Ao pensarmos nas correlaçóes entre os tipos de orientação política e os modos de geração de sentido (e, portanto, também de orientação) histórica, podemos supor que há um traço autoritário comum com a cultura política de sujeição nos modos tradicional, exemplar e genético, uma vez que todos giram em torno de uma verdade rígida que deve ser assimilada e respeitada (modo tradicional), reconhecida por permanência ou continuidade (modo exemplar) ou substituída por outra, mais verdadeira, emergente (modo crítico). Apenas no modo genético, a exemplo do método científico, se concebe uma verdade provisória (apesar de certa para o seu contexto) e dependente de evidências, argumentação e produção de consenso. Trata-se de um condicionamento e não de uma determinação, quer dizer, o caráter histórico-político de uma dada cultura é uma resultante de diversos fatores, e o autoritarismo inerente a uma verdade única e imposta é um fator importante. Mas não é despropositado imaginar, apesar da contradição inerente, que ocorra a imposição de uma verdade única democrática; entretanto, isso não obrigaria as pessoas a desejar uma participação ativa, sendo mais provável uma participação formal e limitada.

É razoável supor que a identificação histórica de um aldeão de um lugar em que o Estado Nacional pouco interfere (ou não existe) seja com uma história concebida como a história da aldeia, de seus parentes e dos conhecidos, e a relação com a política local geralmente significa o seguimento de um líder ou um grupo de líderes locais cuja legitimidade é assumida de forma geralmente náo problemática, natural. Trata-se do tipo paroquial, na cultura política, que está fortemente relacionado com o modo tradicional de geração de sentido histórico. 
Mesmo em sociedades modernas, de certo modo a lógica paroquial/tradicional permanece, convivendo com as demais lógicas mais típicas de períodos posteriores.

A ideia de que as orientações políticas paroquiais correspondem a modos de geração de sentido histórico tradicionais, e que essa articulação se relaciona a um conhecimento/concepção de história como a história da aldeia (por vezes dentro de uma ordem temporal mística como a Cristandade, o Islã etc.), encontra apoio na constatação dos processos educativos escolares dirigidos pelo Estado Nacional no processo de sua consolidação. Ao esforço para ensinar aos aldeóes o padrão linguístico nacional dominante (ANDERSON, 1989, p. 54-55), (HOBSBAWM, 1990, p. 77), podemos adicionar, num momento posterior, o esforço para ensinar uma história nacional (e a universal ou da civilização, dentro da qual a história nacional faz sentido) mais ampla, produzindo paulatinamente o sentido de pertencimento a ela, sobreposto ao pertencimento à aldeia. Nos processos de acelerada industrialização e urbanização, o descentramento e a perda da aldeia tornam mais fáceis a adesão à história nacional, que está ligada à passagem para orientaçôes políticas de caráter autoritário/de sujeição ou democráticos/de participação. A disseminação da imprensa e a distribuição dos jornais permitem, juntamente com a aceleração dos transportes, entre outros fatores, a produçáo de um sentido de simultaneidade e pertencimento a uma comunidade ampla, que integra diversas comunidades locais (ANDERSON, 1989, p. 43).

Por sua vez, uma cultura política participativa/democrática está associada a formas mais sofisticadas de cultura histórica: o que, cognitivamente, é a compreensão da historicidade, na dimensão afetiva/estética é a empatia histórica (seja pela mitigação do estranhamento, seja pela capacidade de compreender o outro em sua diferença) e na dimensão avaliativa/ orientativa/política é a tolerância (no âmbito passivo ou receptivo) ou a disposição para mudanças inovadoras permitidas pela noção de que as nossas identidades e familiaridades são construçôes, e que não é necessário ou obrigatório que sejam assim. As culturas políticas paroquial e de sujeição vivem, porém, sem essa orientação, e sua influência nas sociedades modernas pode ser notada no bairrismo, no regionalismo, na xenofobia. Por outro lado, uma vez que essa orientação genética é concebida e vivida por largas parcelas da população, a imposição de modelos autoritários necessitará de ainda mais coerção para manter-se, ou alternativamente poderá seduzir para atitudes antiempáticas. Tais atitudes serão mobilizadas primeiro por convencer que o outro é um concorrente por recursos escassos e vitais ou uma ameaça à vida dos iguais, em seguida desumanizando-o e, por fim, devotando-lhe um ódio irracional, abaixo do nível cognitivo médio outrora alcançado. 
Figura 1 - Mapa conceitual sobre as articulações entre cultura política e cultura histórica

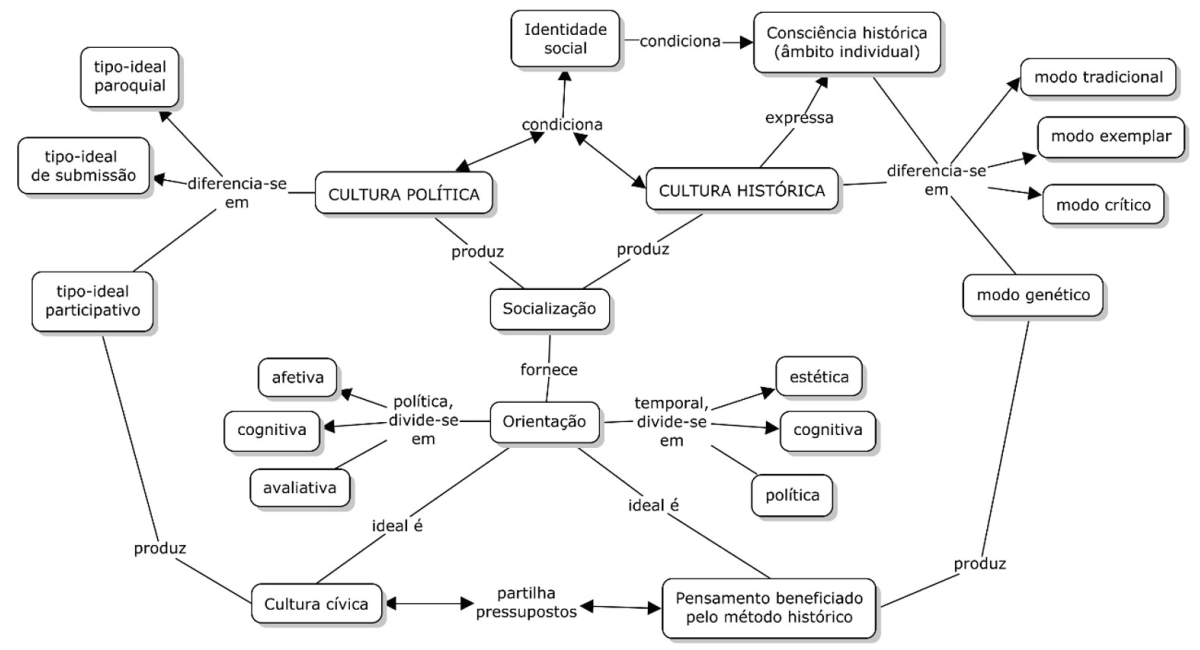

Fonte: Elaborado pelo autor, 2020.

Em resumo (Figura 1), a cultura histórica entra na cultura política ao promover a produção e o consumo de narrativas que deem sentido ao sistema político no tempo, e pode sustentar as formas mais complexas e diversificadas de participação, quando é o caso, e quando se trata de uma cultura histórica ampla e sofisticada. Portanto, os processos de socialização política, de formação de novos cidadãos e educação continuada dos já formados, estão intimamente ligados aos processos de educação histórica.

\section{Esboço de aspectos da cultura histórica em função da cultura política}

Uma abordagem metodológica para a pesquisa da cultura histórica e suas interaçóes com a cultura política depende do estabelecimento de uma agenda de aspectos a investigar, que é o que pretendemos esboçar a seguir.

Já consideramos acima que um dos componentes da cultura histórica está vinculado às diferenciações que o indivíduo faz sobre a história à qual pertence e participa e sobre a história que lhe é externa. O primeiro item, portanto, é a identificação com a história, o reconhecimento de qual é a "sua história”, e de quais histórias estamos fora. A identificação com histórias geralmente se liga à identificação com um corpo político. Participar de uma história não significa necessariamente compreender-se agente dela: posso entender que, embora eu "cozinhe os banquetes da vitória" ou "chore o afundamento da armada" junto com meu soberano, a história é feita numa outra faixa de vida e tempo que não é a minha. Quando alguém se afirma pertencente à nação, mas que a política não é para si ou para gente como ele(a), tem-se aí um dado fundamental da cultura política, em que as concepçóes de história 
(incluindo o papel dos sujeitos e das classes sociais) se ligam profundamente com as concepçôes de agência do indivíduo. Num nível mais profundo de distanciamento, posso pertencer a um país que conta uma narrativa canônica sobre seu passado coletivo que não reconheço como minha. $\mathrm{Na}$ condição de descendentes de vencidos, de escravizados, de imigrantes não aceitos, a trajetória dos acontecimentos e dos próceres não me diz respeito, e a história que reconheço como minha é uma outra.

Outro item é o quanto as pessoas sabem/conhecem de história e o quanto essa história conhecida se estende no tempo e espaço. Lógicas tradicionais/paroquiais geralmente se vinculam a um padrão de conhecimento da história local que está limitado em termos de espaço/tempo, embora seja profundo. Nos casos pré-modernos, esse conhecimento se liga a uma concepçáo de tempo religiosa mais ampla, que é a história canônica que por um lado envolve todo o universo desde a sua criação, mas via de regra esse universo tem por centro a própria Terra (entendida como os continentes dos quais se tem notícia, apenas) e seu âmbito de tempo não ultrapassa meia dezena de milênios.

A amplitude do quanto se sabe de história, associado à amplitude de tempo e espaço ao qual essa história se refere aumenta consideravelmente a chance de alteridade, isto é, de conhecer outras experiências de vida e de organização social, econômica e política bastante distintas da sua própria. Dois usos histórico-políticos podem ser dados a esse conhecimento. Amarrada à autoridade e ao seu código moral, a coletividade pode interpretar a alteridade histórica em termos de certo e errado, de exemplos a seguir ou a evitar; em geral, culturas políticas de sujeição alimentam seus processos de legitimação com essa concepção/relação com a história. Porém, uma vez que essa coletividade enfrente crises internas que afetem a legitimidade do poder dominante de algum modo, a alteridade histórica é o que permite questionar a própria forma de organização, pois concebe que existem outras formas possíveis de organização além da sua, que se torna passível de críticas, sejam pontuais, sejam sistêmicas. Essa concepção/relação com a história está na base de orientações históricas críticas e genéticas, e da orientação política participativa. Ao contrário de Almond e Verba, entretanto, cumpre afirmar que a participação popular em processos de mobilizaçáo sindical e em atos de construção de processos revolucionários e em revoluçôes em si também são formas de participação, mesmo quando levem a Estados autoritários que exijam sujeição.

No âmbito da orientação cognitiva, então, o conhecimento do sistema político passa pela apropriação, no campo da cultura histórica, de uma narrativa mestra, ou seja, "padrôes de interpretação geral que tem a função de produzir sentido para o passado, presente e futuro de uma comunidade cultural", segundo a leitura de Agnes Heller feita por Carretero e Van Alphen (2014, p. 291). Tal narrativa mestra cumpre a função de contextualizar e dar significado ao sistema político no tempo.

Outro aspecto da cultura histórica que necessariamente se relaciona com a cultura política é a dimensão afetiva, que por sua vez se articula com a dimensão estética. Ambas têm 
a ver com o gosto e o interesse, no caso, pela história/pela própria história. O gosto está na base do interesse. Gosta-se ou desgosta-se inclusive daquilo que praticamente não se conhece, pela projeção do gosto pelos indícios do que aquela história parece ou promete ser.

No âmbito da orientação afetiva, o conhecimento em história (ou a falta dele em determinados temas ou recortes) pode aproximar ou distanciar os sujeitos do gosto ou do interesse por seu próprio sistema político. Por exemplo, é razoável supor que a indiferença ou a desconfiança quanto ao sistema político na sociedade brasileira, que tem feito manifestar um persistente antagonismo entre representantes e representados, tem em suas raízes a alienação em relação à história nacional. Em outros termos, se as origens do Estado e do governo na atualidade estão na história, mais especificamente na narrativa mestra ou na narrativa canônica da história nacional, é possível defender que o distanciamento em relação a essas narrativas está vinculado ao afastamento, desconfiança e antagonismo em relação ao sistema político.

A socialização histórico-política das crianças e jovens para a participação nas instituições do Estado ocorre na escola, e a internalização da narrativa mestra como uma narrativa à qual se pertence e que organiza o pano de fundo da própria história pessoal e a familiar nos parece condição básica. A tardia universalização da educação básica no Brasil, bem como a persistência de altos índices de evasão e de aprendizado insuficiente, e ainda uma história nacional em que negros, indígenas, pardos, pobres, migrantes não estão representados ou aparecem de modo marginal, são fatores que muito provavelmente colaboram para o afastamento em relação ao sistema político brasileiro, no que tange à orientação cognitiva, afetiva. Consequentemente, a orientação avaliativa, que define a atitude em relação ao sistema político, tem este nome exatamente porque a avaliação do sistema precede a ação, envolve uma avaliação de como é ou como deixa de ser a participação popular que o sistema estrutura. Para o exemplo que estamos utilizando, a omissão ou a atitude antagonista e destrutiva em relação ao sistema pode ter ligaçôes com a aprendizagem de uma história que exclui ou coloca em último plano o cidadão comum, quando trata da política, relegando-o no máximo à condição de confirmador passivo das autoridades.

Em todos os casos, o orgulho nacional, que é componente fundamental da cultura política, tem profundas raízes nos aspectos afetivos da cultura histórica, e pode variar em intensidade e substância, ou seja, pode ser maior ou menor e, sendo negativo, como vergonha, tenderá a alienar o sujeito em relação ao sistema político ao qual essa história nacional se liga.

Das consideraçóes acima, podemos incluir no elenco de características da cultura histórica que se relacionam com a cultura política o tipo e a intensidade das relaçóes entre passado e presente concebidas pelos sujeitos ou grupos. Uma cultura histórica descontínua estabelece poucas e pouco intensas relações com o passado, ou seja, o passado é conhecido, mas as relações entre passado e presente são frágeis, confusas ou inexistentes. Percebe-se essa característica em movimento principalmente na indignação com o fato de que a maioria da população não saiba o motivo histórico de um dia feriado, ou quem foi o personagem que 
dá nome a uma rua importante da cidade. Claro que essa indignação parte dentre aqueles poucos que tiveram acesso a essa informação e consideram esse passado relevante para constar no presente.

A qualidade da relação com o passado é uma característica da cultura histórica que se liga com outra, a do conhecimento ou ignorância do passado, mas o próprio fato de não haver esforços bem-sucedidos dos órgáos do Estado em preservar e disseminar tal passado é um indicativo, seja da perda da importância de uma narrativa, seja da predominância da fraqueza das ligaçóes com o passado como um todo. Ele é visto como um continente isolado, do qual viemos, mas que deixamos em outra parte e náo temos mais ligaçôes relevantes. Um dos indicadores de descontinuidade é o grau de confiança ou desconfiança em relação à história que se aprendeu, ou seja, o quanto o sujeito considera fidedigna a história que lhe foi ensinada, e o quanto considera que lhe ocultaram da "verdadeira" história. Embora seja uma das bases do pensamento crítico em relação ao conhecimento, e fator central para o aperfeiçoamento da história, um sentimento de desconfiança envolvente e predominante é condição para a adesão a teorias conspiracionistas, que escapam da alçada do pensamento racional por estabelecerem, por meio de afirmaçôes não falseáveis ou verificáveis, uma leitura dogmática do mundo.

Em oposição à característica de descontinuidade com o passado, estaria uma relação de continuidade, em que está ativo e fluente o estabelecimento de relaçóes entre os processos do passado conhecido e a vida no presente, tanto como fator de causaçáa, quanto de ruptura. A ruptura aqui não é como aquela alienação da descontinuidade, a qual pressupõe indiferença, mas uma atitude ativa, de contraposição, isto é, se rejeitamos o passado e procuramos construir o seu oposto no presente, trata-se de um modo de continuidade por meio da oposição. Essa continuidade, no que tange à qualidade da relação com o presente tanto pode ser positiva (como na frase "os pais fundadores e sua obra são a base do modo americano de vida”), quanto negativa, quando predomina a ideia de que o grupo político já passou por sua idade de ouro, e seu presente é um estado de decadência à espera de uma redenção (que aliás emula o enredo judaico-cristáo do paraíso perdido versus redenção). Sempre, insistimos, rejeitando uma abordagem determinista das relaçôes entre cultura histórica e cultura política, e uma hierarquização axiológica dos tipos e formas de cultura histórica e cultura política.

A cultura histórica pode ser mais ou menos influenciada pela cultura historiográfica. Quando ela falta ou não está disseminada, multiplicam-se modos estereotípicos de relação com o passado, em que se reconhecem as continuidades, mas seus sentidos são sustentados de argumentos e raciocínios pobres e preconceituosos em que os elementos não foram submetidos a nenhum escrutínio crítico ou fundamentado. Por exemplo, a ideia de que o Brasil é pobre porque os povos que o compóem não são afeitos ao trabalho, ou que predomina a corrupçáo porque os primeiros colonizadores eram os criminosos degredados, ou que o Brasil seria mais democrático e próspero se nossa colonização fosse feita pela Holanda ou 
França em vez de Portugal. Sem perder de vista que os enunciados aceitos como científicos do passado, embora desacreditados hoje, podem permanecer informando narrativas na atualidade, podemos falar também de influência de uma cultura historiográfica datada, superada. É o que ocorre, por exemplo, com formulaçôes residuais de eugenia e darwinismo social, que sustentam narrativas racistas como as que entendem que as regióes em que predomina a colonização alemã ou italiana (ou outra à escolha do falante) seriam mais ricas ou mais honestas ou mais trabalhadoras do que as outras porque seriam compostas de material humanamente superior em relação a outras regióes. De modo mais velado ou mais explícito, essa é a base de cultura histórica para movimentos separatistas que se aguçam ou que se apagam conforme a conjuntura política do momento.

Os modos de percepçáo do passado no presente e na vida cotidiana constituem mais um item a ser considerado na pesquisa sobre a cultura histórica. Aqui, diferenciamos consciência da história (que seria o grau de atenção ou de alcance do olhar aos objetos históricos, em termos náo pessoais), de consciência histórica (que seria o processo de atribuição de sentidos ao tempo vivido, em termos pessoais). O passado participa do presente de diversas formas, entretanto é bastante variável a percepçáo de como isso se dá em diferentes culturas ou formas de organização coletiva. A pergunta sobre como, quanto um sujeito concebe/percebe do impacto da história em sua vida refere-se a isso, à con-ciência (no sentido de notar, saber, estar ciente) do passado informando, condicionando, determinando, estimulando o presente e as projeções de futuro. A geração tradicional de sentido tem sua expressão ideal-típica quando o passado mal é percebido como tal (RÜSEN, 2001, p. 77).

A geração genética de sentido histórico, por outro lado, corresponderia àquilo que Gadamer chamou de consciência histórica, propriamente, cuja relação com o passado caracteriza-se pela "[...] plena consciência da historicidade de todo o presente e da relatividade de toda opiniāo", o que seria um "privilégio do homem moderno" (GADAMER, 1998, p. 17). Entre tradicional e genético, se colocam formas progressivamente complexas da consciência do passado e sua presença no presente. A isto se liga a noçáo de "herança" histórica, seja como impulso, seja como fardo, bem como de determinação, condicionamento ou autonomia em relação ao passado.

Uma dimensão relevante para a caracterização da cultura histórica, ainda, é o aspecto avaliativo, ou a orientação para a ação (política, principalmente), que ela permite. Dizendo de outra forma, como (com que precisão, com que consistência entre representação e empiria) o indivíduo se localiza no tempo, espaço e no tecido social, em que grau consegue articular os eventos da história macro com os acontecimentos micro, os que envolveram/envolvem a si, sua família e comunidade mais próxima, ou a seus antepassados. Por exemplo, entender-se como filho de Deus e membro útil da cristandade é uma representaçáo calcada em elementos histórico-políticos que tem um significado completamente diferente para um camponês no interior da Espanha, um senhor de engenho no Brasil ou um indígena vivendo em uma mis- 
são, todos no século XVII. Consciência negra em um país racista que preza pela negação do racismo se liga a uma representação crítica da história. Ou ainda, a concepção canônica da história pela qual "Deus proverá" leva a uma avaliação e um posicionamento político quanto ao aquecimento global, por exemplo, que será contraproducente aos esforços políticos e diplomáticos para a redução de emissão de gases de efeito estufa.

Quadro 2 - Componentes e oposiçóes da cultura histórica em função da cultura política*

\begin{tabular}{|c|c|c|c|c|c|}
\hline Componentes & \multicolumn{5}{|c|}{ Oposiçóes } \\
\hline Relaçáo de si com a & \multicolumn{3}{|c|}{ Interna } & \multirow{2}{*}{\multicolumn{2}{|c|}{ Externa }} \\
\hline $\begin{array}{l}\text { narrativa mestra ou } \\
\text { canônica do corpo }\end{array}$ & \multicolumn{2}{|c|}{ sujeito ativo } & \multirow[t]{2}{*}{ sujeito passivo } & & \\
\hline naçáo) & \multicolumn{2}{|c|}{ Confiança } & & \multicolumn{2}{|c|}{ Desconfiança } \\
\hline $\begin{array}{l}\text { Relação cognitiva } \\
\text { com o passado }\end{array}$ & \multicolumn{3}{|c|}{ Saber } & \multicolumn{2}{|c|}{ Não saber } \\
\hline $\begin{array}{c}\text { Relaçáo com a } \\
\text { alteridade histórica }\end{array}$ & \multicolumn{3}{|c|}{ Certo versus errado } & \multicolumn{2}{|c|}{$\begin{array}{l}\text { Fontes para conhecimento e } \\
\text { crítica de si e do grupo }\end{array}$} \\
\hline \multirow{2}{*}{$\begin{array}{l}\text { Relação passado - } \\
\text { presente - futuro }\end{array}$} & \multicolumn{3}{|c|}{ Descontínua } & \multicolumn{2}{|c|}{ Contínua } \\
\hline & $\begin{array}{c}\text { por } \\
\text { ignorância }\end{array}$ & $\begin{array}{r}\text { po } \\
\text { rejei }\end{array}$ & $\begin{array}{c}\text { por conveniên- } \\
\text { cia/ cinismo }\end{array}$ & por adesão & por oposição \\
\hline \multirow[b]{2}{*}{$\begin{array}{l}\text { Relação com a cultura } \\
\text { historiográfica }\end{array}$} & \multicolumn{3}{|c|}{$\begin{array}{l}\text { Desatualização (representação estereo- } \\
\text { tipada/anacrônica/voluntarista etc.) }\end{array}$} & \multicolumn{2}{|c|}{ Atualizada } \\
\hline & Não intenc & onal & $\begin{array}{l}\text { Intencional } \\
\text { (revisionista) }\end{array}$ & $\begin{array}{l}\text { Comunicativa, } \\
\text { argumentativa }\end{array}$ & $\begin{array}{l}\text { Hermética } \\
\text { (aceitação por } \\
\text { autoridade) }\end{array}$ \\
\hline
\end{tabular}

Fonte: Elaborado pelo autor, 2020.

* Para cada oposição é pressuposto um campo intermediário entre os polos estabelecidos, bem como a presença concomitante das duas situaçóes em proporções variáveis.

\section{Considerações finais}

Retomamos neste ponto o que foi afirmado na introdução: a função deste texto, longe de querer esgotar ou abranger todos os aspectos da questão proposta, é a de operar como convite ao debate e à reflexão. Para isso, o primeiro destaque, a título de síntese, é o papel da identidade como elemento que articula em primeira instância a cultura histórica e a cultura política. Entendida como elemento de disputa política e social, a questão da(s) identidade(s) é um dos fatores que justifica a importância, e mesmo a urgência do tipo de estudo aqui proposto. Trata-se de uma perspectiva na qual a reflexão didática sobre a história (ou seja, o estudo da produção, circulação e consumo de conteúdos históricos) carrega o potencial de ampliar o espaço de contribuição do campo da história para a produçáo de conhecimentos nas ciências humanas, em articulação interdisciplinar com a ciência política. 
A tarefa que se impóe como sequência desse debate é a elaboração de metodologias que permitam a coleta e a análise de dados junto aos sujeitos de pesquisa. No que tange à elaboração de instrumentos para coleta empírica de dados para o estudo da cultura histórica em suas relaçóes com a cultura política, procuramos demonstrar as várias camadas de leituras de mundo, atitudes e possibilidades de posicionamento que podem ser transformadas em perguntas, situaçóes-problema, afirmaçóes ou outras formas de interação com os entrevistados ou com as fontes pré-existentes. A combinação de instrumentos quantitativos, em que as leituras, atitudes e posicionamentos gerais podem ser capturados e caracterizados para grandes números de respondentes, permite o estabelecimento de panoramas e a descoberta de correlaçóes que não seriam visíveis "a olho nu”, ou seja, a partir da percepção individual ou de grupos de pessoas com pensamento parecido. Os estudos qualitativos, a partir desses levantamentos, estabelecem a contribuição inestimável de um aprofundamento nas causas, razóes e argumentos dos indivíduos e pequenos grupos, permitindo identificar e equacionar a compreensão dos processos sociopolíticos recentes e/ou em curso.

As conclusóes dos estudos vindouros, por sua vez, também contribuirão para revisar as propostas teórico-metodológicas de abordagem da interface entre a cultura histórica e a cultura política esboçadas neste ensaio.

\section{Referências}

ALMOND, Gabriel; VERBA, Sidney. The Civic Culture Revisited. Boston: Little; Brown, 1980.

ALMOND, Gabriel; VERBA, Sidney. The Civic Culture Political Attitudes and Democracy in Five Nations. 3. ed. Londres: SAGE Publications, 1989.

ANDERSON, Benedict. Nação e consciência nacional. São Paulo: Ática, 1989.

BERGMANN, Klaus. A história na reflexão didática. Revista Brasileira de História, São Paulo, v. 9, n. 19, p. 29-42, 1990.

BORBA, Julian; CARDOSO, Gabriela Ribeiro. Os estudos de comportamento político na ciência política brasileira: caracterização do campo, apontamentos sobre a literatura e trabalhos de referência. Revista Brasileira de Informação Bibliográfica em Ciências Sociais, [s. 1.], n. 89, p. 1-33, 2019.

CABRERA CABRERA, Valéria. Cultura política e teoria política: dialogar para problematizar. RELACult - Revista Latino-Americana de Estudos em Cultura e Sociedade, [s. 1.], v. 5, n. ed. especial, p. 1-17, 2019.

CARRETERO, Mario; VAN ALPHEN, Floor. Do Master Narratives Change Among High School Students? A Characterization of How National History Is Represented. Cognition 
and Instruction, [s. 1.], v. 32, n. 3, p. 290-312, 2014. Disponível em: http://dx.doi.org/10.1 080/07370008.2014.919298

FLORES, Elio Chaves. Dos feitos e dos ditos: história e cultura histórica. Saeculum, Revista de História, [s. 1.], v. 16, p. 83-102, 2007. Disponível em: http://www.periodicos.ufpb.br/ ojs2/index.php/srh/article/view/11374/6488. Acesso em: 19 jun. 2019.

GADAMER, Hans Georg. O problema da consciência histórica. 1. ed. Rio de Janeiro: Editora da FGV, 1998.

GASPARELLO, Arlette Medeiros. O livro didático como referência de cultura histórica. In: ROCHA, Helenice; MAGALHÃES, Marcelo; GONTIJO, Rebeca (orgs.). A escrita da história escolar. Memória e historiografia. 1. ed. Rio de Janeiro: Editora da FGV, 2009. p. 265-280.

GOMES, Angela Maria de Castro. A cultura historica do Estado Novo. Projeto História, [s. 1.], v. 16, p. 121-141, 1998.

GOMES, Angela Maria de Castro. Cultura política e cultura histórica no Estado Novo. In: ABREU, Martha; SOIHET, Rachel; GONTIJO, Rebeca (orgs.). Cultura politica e leituras do passado: historiografia e ensino de história. 1. ed. Rio de Janeiro: Civilização Brasileira, 2007. p. 43-63.

HELLER, Agnes. Uma teoria da história. Rio de Janeiro: Civilização Brasileira, 1993.

HOBSBAWM, Eric J. Naçôes e nacionalismo desde 1780 - programa, mito e realidade. Rio de Janeiro: Paz e Terra, 1990.

LEVITSKY, Steven; ZIBLATT, Daniel. Como as democracias morrem. Rio de Janeiro: Zahar, 2018. MARTINS, Estevão de Rezende. Processos históricos, aprendizagem e educação de uma "segunda natureza humana”. Educ. rev., Curitiba, n. 60, p. 73-91, 2016.

NEVES, Joana. Participação da comunidade, ensino de história e cultura histórica. Saeculum, Revista de História, [s. 1.], v. 6/7, n. jan./dez., p. 35-47, 2001.

OLIVEIRA, Itamar F.; OLIVEIRA, Margarida M. D. Cultura histórica e livro didático ideal: algumas contribuiçóes de categorias rüsenianas para um ensino de história à brasileira. Espaço Pedagógico, v. 21, n. 2, p. 223-234, 2014.

PAVONE, Tommaso. Political Culture and Democratic Homeostasis: a Critical Review of Gabriel Almond and Sidney Verba's The Civic Culture Background on Structural Functionalism. Princeton [s. n.] Disponível em: https://scholar.princeton.edu/sites/default/ files/tpavone/files/almond_verba-_the_civic_culture_critical_review_0.pdf. Acesso em: 4 jun. 2019.

PAVONE, Tommaso. Almond \& Verba, eds. The Civic Culture Revisited. Princeton [s. n.] Disponível em: https://scholar.princeton.edu/sites/default/files/tpavone/files/almond_ verba-the_civic_culture_revisited_summary.pdf. Acesso em: 4 jun. 2019. 
RANCIÈRE, Jacques. O ódio à democracia. São Paulo: Boitempo, 2014.

ROCHA, Helenice; MAGALHÃES, Marcelo; GONTIJO, Rebeca (orgs.). O ensino de história em questão: cultura histórica, usos do passado. Rio de Janeiro: Editora da FGV, 2015. RÜSEN, Jorn. História viva. Teoria da História III: formas e funçôes do conhecimento histórico. 1. ed. Brasília: Editora da UnB, 2007.

RÜSEN, Jörn. Razão histórica - Teoria da História: os fundamentos da ciência histórica. 1. ed. Brasília: Editora da UnB, 2001.

RÜSEN, Jörn. Teoria da História. Uma teoria da história como ciência. 1. ed. Curitiba: Editora da UFPR, 2015.

SCHMIDT, Maria A. M. S. Cultura histórica e cultura escolar: diálogos a partir da educação histórica. História Revista, v. 17, n. 1, p. 91-104, 2012.

SCHMIDT, Maria A. M. S. Cultura histórica e aprendizagem histórica. Revista NUPEM, v. 6, n. 10, p. 31-50, 2014.

SOUZA, Éder C. Cinema, cultura histórica e Didática da História: repensar a relação entre filmes e conhecimento histórico. Revista de Teoria da História, v. 6, n. 12, p. 202-229, 2014. SWEDLOW, Brendam. Political Culture. In: CLAEYS, Gregory (org.). Encyclopedia of Modern Political Thought. [s. 1.]: CQ Press, 2012. p. 624-625.

WANDERLEY, Sônia M. A. I. Cultura histórica, mídia e ensino de história: problemas políticos de ensinar e aprender. Anais do XIV Encontro Regional de História da ANPUH-RJ. São Gonçalo, ANPUH-RJ, 2012. 